This item was submitted to Loughborough's Institutional Repository (https://dspace.lboro.ac.uk/) by the author and is made available under the following Creative Commons Licence conditions.

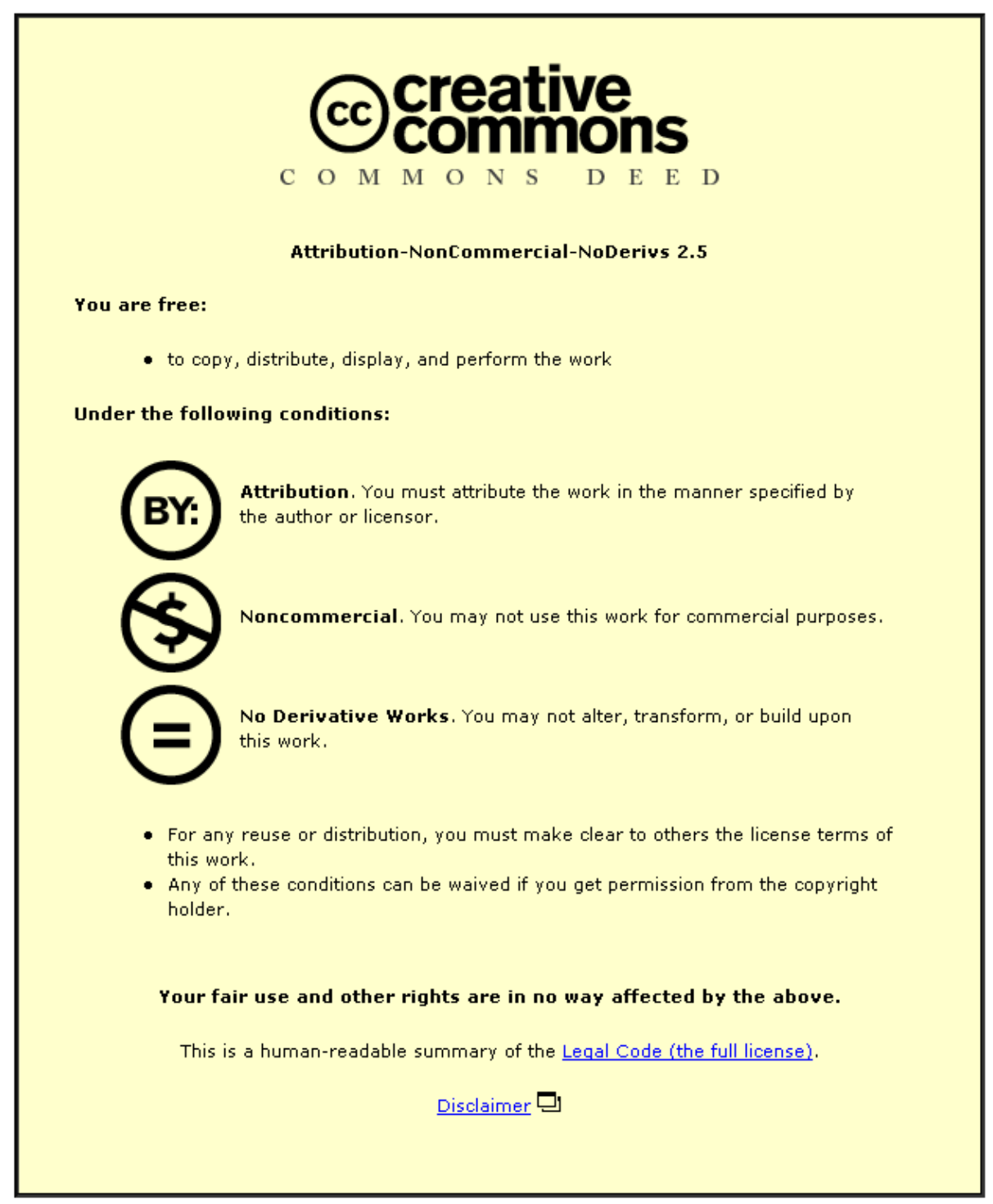

For the full text of this licence, please go to: http://creativecommons.org/licenses/by-nc-nd/2.5/ 


\title{
Irradiation-Induced Precipitation Modelling of Ferritic
}

\author{
Steels \\ You Fa Yin, Roy G Faulkner and Zheng Lu \\ Institute of Polymer Technology and Materials Engineering, Loughborough University, \\ Ashby Road, Loughborough University, Leicestershire LE11 3TU, UK
}

\begin{abstract}
In high strength low alloy (HSLA) steels typically used in reactor pressure vessels (RPV), irradiation induced microstructure changes affect the performance of the components. One such change is precipitation hardening due to the formation of solute clusters and/or precipitates which form as a result of irradiation enhanced solute diffusion and thermodynamic stability changes. The other is irradiation enhanced tempering which is a result of carbide coarsening due to irradiation enhanced carbon diffusion. Both effects have been studied using a recently developed Monte Carlo based precipitation kinetics simulation technique and modelling results are compared with experimental measurements. Good agreements have been achieved. PACS: 61.82.Bg, 61.80.-x, 61.80.Hg, 61.82.-d.
\end{abstract}

\section{Introduction}

Several studies exist of the precipitate distribution in pressure vessel steels used for nuclear reactor applications [1-4]. In addition, Buswell [5] completed a comprehensive metallographic study of such materials in 1983 . The steels are typically C-Mn steels or MnMoNi steels, but some with a certain amount of unintended copper. The $\mathrm{Ni} / \mathrm{Cu}$ ratio has been recognised as a critical parameter in controlling the response of the 
microstructure to neutron irradiation. The experimental observations confirm that there are three major types of precipitate seen in both unirradiated and irradiated materials. These are $\mathrm{Fe}_{3} \mathrm{C}, \mathrm{Mo}_{2} \mathrm{C}$, and a strained copper-rich phase with a basic $\mathrm{BCC}$ crystal structure. $\mathrm{Mn}$ and $\mathrm{Ni}$ also play a role in determining the stability of the $\mathrm{Cu}$-rich phase, where fewer $\mathrm{Cu}$ atoms are associated with such cluster phases and the levels of $\mathrm{Mn}$ and Ni are raised [2].

In recent years progress in building models of precipitation as a function of time and temperature has been highly successful. The thermodynamic data for determining the relative stabilities of different phases in commercial alloys has become available in digital format through such packages as Thermocalc, Dictra, and MTDATA [6]. The mechanisms for nucleation and growth have become better understood and considerable progress has been made with identifying the mechanisms of heterogeneous nucleation and growth, particularly on grain boundaries. This has allowed the development of iterative computer-based analysis of the kinetics of nucleation and growth of precipitates in a wide range of metallic materials. One such model proposed by Yin and Faulkner [7, 8] allows the prediction of precipitate size, volume fraction, and inter-precipitate spacing as a function of both time and temperature. The separate precipitation sequences at grain boundaries and within the grains also can be considered in the model. This is a very powerful tool because the evolving precipitate size distribution information can be fed directly to continuum damage mechanics models of high temperature mechanical strength and the result is that the precipitation models can be used to predict creep rate at any specified time and temperature. Thus, creep life can be forecast. This provides a very effective tool in assisting alloy design with respect to providing materials with improved creep strength 
$[9,10]$. As mentioned earlier, the underlying thermodynamics of the precipitate evolution are provided by powerful software which analyses the stability of all potential phases at the temperature concerned and in the alloy of interest. Small changes in chemical composition can alter the thermodynamic stabilities by considerable amounts, and these factors are accurately taken into account in the thermodynamic assessment. There is also the prospect of feeding the evolving precipitate distribution into hardening models and combining fracture initiator distribution to give fracture toughness distributions.

Previously, phase transformations under irradiation had only been treated in a semiquantitative fashion [11]. Until this current work was undertaken, no attempts had been made to accurately alter the thermodynamics of phases present as a function of neutron irradiation effects. In principle this should be straightforward, so long as the additional energy input to the system coming from the neutron irradiation is known. The effects of introducing this energy to thermodynamic modelling of ferritic steels have been reported [12]. The main findings were the reversion of approximately $25 \%$ of the ferrite to austenite under high dose, fast reaction neutron energy spectrum irradiation conditions $(E>1 \mathrm{MeV})$. These results were confirmed experimentally. However, the characteristics of the remaining ferrite do not differ very much from those without the extra energy input, i.e. without irradiation.

It is also well known that irradiation generates a high density of vacancies in the material and this results in faster diffusion of solute atoms within the material. This paper shows that the effect of irradiation enhanced diffusion can be introduced to the precipitation kinetics model and that the model output reflects well the real situation 
for second phase particles in irradiated steels. Examples of the application of the new method to RPV steels will be given and the effects of the predicted differences in precipitate distribution as a function of $\mathrm{Ni} / \mathrm{Cu}$ ratio and absolute $\mathrm{Ni}$ concentration will be highlighted.

\section{Model details}

\section{Precipitation model}

The precipitation model has been described in full detail elsewhere [7, 8]. However, a brief description is given here below.

The model considers the formation of inter- and intra-granular precipitates separately. The grain boundary precipitates are assumed to nucleate on a random grain boundary with the initial solute concentration determined by the equilibrium and non-equilibrium grain boundary segregation components. This contribution depends on the temperature of the service conditions and on the cooling rate employed in any initial heat treatments used to either solution treat or normalise the alloy [13].

Nucleation kinetics are assumed to obey the Russell-based laws [14], and the precipitates are assumed to be cap-shaped with a contact angle with the precipitate and the grain boundary of $57^{0}$. The activation energy for nucleation, $\Delta G^{*}$, and the nucleation rate, $I$, are as follows. 


$$
\begin{gathered}
\Delta G^{*}=\frac{16 \pi \sigma_{\alpha \theta}^{3}}{3 \Delta G_{V}^{2}} K_{j} \\
I=Z \beta^{*}\left(\frac{N}{x_{\theta}}\right) \exp \left(-\frac{\Delta G^{*}}{k T}\right) \exp \left(-\frac{\tau}{t}\right)
\end{gathered}
$$

where $\sigma_{\alpha \theta}$ is the nucleus-matrix interfacial energy, $K_{j}$ is a shape factor, equal to unity for a sphere, and $\Delta \mathrm{G}_{\mathrm{v}}$ is the driving force for the transformation. $Z$ is the Zeldovitch factor, concerned with the rates of change of phase free energy with temperature, $\beta^{*}$ is the rate at which solute atoms are added to the nucleus, $N$ is the number of atomic nucleation sites per unit volume, $x_{\theta}$ is the mole fraction of solute atoms in the nucleus, $k$ is Boltzmann's constant, $T$ is the absolute temperature, $t$ is time and $\tau$ is the incubation time for nucleation. Usually $\tau$ is very small (1-2 s) and so for realistic ageing times the exponential term tends to unity.

The model constructs an array of potential nuclei using a Monte Carlo metropolis algorithm so that a distribution of spatially defined particles are formed and monitored throughout the lifetime of the material at the temperature concerned. The whole model uses an iterative procedure so that the service/ ageing sequence is divided into a series of small steps, and the driving forces for nucleation are re-considered at each step. Because the reducing solute concentration reduces the activation energy for nucleation, $\Delta G^{*}$, and reduces the supply term, $\beta^{*}$, the nucleation rate rapidly drops to zero and growth takes over.

Growth is determined by the diffusion constants for the slowest moving solute species and the concentration gradient existing between the matrix solute level and the interface concentration in equilibrium with the precipitate phase and the matrix at the 
temperature concerned. The volume increase, $\Delta V$, of a particle in time, $\Delta t$, is calculated by

$$
\Delta V=D S g \frac{\rho_{\theta}}{c_{\theta} \rho_{\theta}-c_{r} \rho_{\alpha}} \Delta t
$$

where $D$ is the diffusion coefficient of the slowest moving solute species, $S$ is the surface area of the particle, either on the plane of the grain boundary or within the grains.

In the case of inter-granular precipitation, part of the contribution to growth from $S$ comes from the collector plate area in the plane of the GB and is fed by the grain boundary diffusion coefficient; the remainder comes from the surface area of the precipitate within the grain fed by the lattice diffusion coefficient. $\rho_{\theta}$ and $\rho_{\alpha}$ are the molar density of the precipitate phase and the matrix respectively. $c_{r}$ is the solute interface equilibrium composition allowing for the Gibbs-Thomson curvature effect and $c_{\theta}$ is the solute concentration in the precipitate phase. $g$ is the concentration gradient determined by

$$
g=\frac{c_{t}-c_{r}}{d}
$$

where $d$ is the mean inter-particle spacing and $c_{t}$ is the mean matrix solute composition at the particular time being considered and is calculated using

$$
c_{t}=1-\frac{V_{f} \rho_{\theta} N_{r}}{\rho_{\alpha} c_{g}}
$$

where $V_{\mathrm{f}}$ is the volume fraction of precipitate, $N_{r}$ is the number of rate controlling atoms per precipitate molecule, and $c_{g}$ is the initial matrix grain solute concentration. 
The concentration, $c_{r}$, is determined by the heats and entropies of formation, the radius of the precipitate, and the Gibbs Thomson curvature effect, which depends on this radius of curvature of the precipitate.

$$
c_{r}=c_{\infty} \exp \left(\frac{2 \sigma_{\alpha \theta} V_{\theta}}{R T r}\right)
$$

where $\sigma_{\alpha \theta}$ is the particle-matrix interfacial energy, $V_{\theta}$ is the molar volume of the precipitate phase . $c_{\infty}$ is the equilibrium solute interface concentration determined from thermodynamic data contained within the MTDATA software [6]. MTDATA is adapted in this work to take account of irradiation-induced phase instability. The method used is described in [12].

Intra-granular precipitation is modelled in an analogous manner simultaneously with the inter-granular precipitation, so that the correct matrix solute concentration is maintained at each time step allowing for precipitation in the grains and on the grain boundaries. Nucleation assumes spherical particles and the solute supply is controlled by the lattice diffusion coefficient for the slowest moving solute species.

Coarsening is automatically considered for both inter- and intra-granular growth through an appreciation of the changing matrix solute contents as growth proceeds. The equilibrium interface solute concentration is also a function of the particle radius, through the Gibbs-Thomson effect (equation (6)). Thus, after a certain time the equilibrium level exceeds the matrix concentration for small particles, and these particles dissolve because of their associated negative concentration gradients. On the other hand, the large particles continue to grow because of their associated positive concentration gradients. This is coarsening, and because the equilibrium and matrix 
solute concentrations are monitored at each time step, it is therefore automatically allowed for in the model.

\section{Calculation of irradiation-assisted diffusion}

The additional vacancies and self interstitials created during the neutron irradiation process can assist various diffusion processes. In particular we concentrate on the vacancies, which are considered essential in thermal diffusion processes. Faulkner and Fisher [15], amongst others, quantified the relationship between the neutron dose and the radiation-enhanced diffusion coefficient using the following approach.

The irradiation enhanced diffusion coefficient, $D_{s v}$, is given by

$$
D_{s v}=D_{s}^{T}\left(\frac{c_{v}^{e}+c_{v}^{r}}{c_{v}^{e}}\right)
$$

where $D_{s}{ }^{T}$ is the thermal diffusion coefficient at the temperature $T . c_{v}{ }^{e}$ is the equilibrium vacancy concentration at the temperature concerned, and $c_{v}^{r}$ is the radiation enhanced vacancy concentration, which is dependent of a variety of factors such as neutron dose, recombination efficiency, and point defect generation efficiency. $D_{s}{ }^{T}$ and $c_{v}{ }^{e}$ can be determined using the following:

$$
\begin{gathered}
D_{s}^{T}=D_{o s}^{T} \exp \left(\frac{-E_{s}^{T}}{k T}\right) \\
c_{v}^{e}=A_{v} \exp \left(\frac{-E_{f}^{v}}{k T}\right)
\end{gathered}
$$

where $D_{o s}{ }^{T}$ is the pre-exponential constant for thermal diffusion and $E_{s}{ }^{T}$ is the activation energy for thermal diffusion. $A_{v}$ is the constant characterising the vibrational 
entropy of the atoms around the vacancy, and $E_{f}^{v}$ is the vacancy formation energy. The irradiation-created vacancy concentration is given by

$$
c_{v}^{r}=\frac{B G F(\eta)}{D_{v} k_{d v}^{2}}
$$

where $B$ is the proportion of free vacancy remaining after the collision cascade and $G$ is the point defect generation rate. In Eqn. (6), the recombination efficiency is given by

$$
F(\eta)=\frac{2}{\eta}\left[(1+\eta)^{1 / 2}-1\right]
$$

and

$$
\eta=\frac{4 \lambda B G}{k_{d v}^{2} k_{d I}^{2} D_{v} D_{I}}
$$

where $D_{I}$ is the self-interstitial diffusion coefficient. The vacancy sink efficiency is

$$
k_{d v}^{2}=\rho^{1 / 2}\left(\frac{6}{R}+\rho^{1 / 2}\right)
$$

where $R$ is the grain diameter and $\rho$ is the dislocation density. And the self-interstitial sink efficiency is

$$
k_{d I}^{2}=\left(Z_{I} \rho\right)^{1 / 2}\left[\frac{6}{R}+\left(Z_{I} \rho\right)^{1 / 2}\right]
$$

where $Z_{I}$ is the self-interstitial bias factor describing the preferential attraction of interstitials to dislocations, compared to vacancies.. The long range recombination rate of the freely migrating defects, $\lambda$, is given by

$$
\lambda=\frac{21 D_{I}}{b^{2}}
$$

where $b$ is the jump distance of the self-interstitials. The vacancy and self-interstitial diffusion coefficients are given by 


$$
\begin{aligned}
& D_{v}=D_{o v} \exp \left(\frac{-E_{m}^{v}}{k T}\right) \\
& D_{I}=D_{o I} \exp \left(\frac{-E_{m}^{I}}{k T}\right)
\end{aligned}
$$

and the dislocation density, $\rho$, is assumed to be an irradiation-enhanced value, based on the initial equilibrium value at the temperature concerned, $\rho_{0}$.

$$
\rho=\rho_{0} \exp \left(\frac{E_{d}}{k T}\right)
$$

$D_{0 v}$ and $D_{0 I}$ are the pre-exponential coefficients for vacancy and self-interstitial diffusion respectively, and $E_{m}{ }^{v}$ and $E_{m}{ }^{i}$ are the migration energies for vacancy and selfinterstitials respectively.

\section{Materials, heat treatment, irradiation and modelling parameters}

Three alloys have been studied and their compositions are listed in Table 1. Main parameters used in the precipitation kinetics modelling and irradiation enhanced diffusion calculations are shown in Table 2 and 3 respectively. The heat treatment sequence used in the modelling involves heat treating the steel at $600{ }^{\circ} \mathrm{C}$ for 42 hours and then tempering at $650^{\circ} \mathrm{C}$ for 6 hour, followed by irradiation at $255^{\circ} \mathrm{C}$ for the times shown on the timescale.

\section{Results and discussion}

Irradiation assisted iron carbide coarsening

Fig. 1 shows simulated (lines) volume fraction (a) and the particle size (b) of intergranular $\mathrm{Fe}_{3} \mathrm{C}$ as a function of time in ALLOY B (high Ni-high $\mathrm{Cu}$ ). In the simulation 
of $\mathrm{Fe}_{3} \mathrm{C}$, the rate-controlling element is assumed to be carbon, since there is always a large reservoir of $\mathrm{Fe}$ available to promote particle nucleation and growth anywhere within the material. Symbols are experimental measurements reported in [5] and [16]. Reasonable agreement is seen when comparing the simulated and the measured size of the particles.

The size and volume fraction curves show several non-linear steps. Values are calculated for the appropriate temperatures of the stress relieving, tempering, and irradiation treatments, all on the same time scale. The nucleation and growth of the carbides finishes during the stress relieving treatment as indicated by the plateaus in the curves. The start of the first reduction corresponds to the end of the stress relieving treatment at $600{ }^{\circ} \mathrm{C}$ when the material is subjected to the tempering treatment at $650{ }^{\circ} \mathrm{C}$. The higher tempering temperature causes an increase in the solubility of carbon. This means some carbon in the carbides has to dissolve into the matrix and therefore the volume fraction of carbide formed and the size of the carbides are reduced. Subsequent irradiation/thermal control treatment at $255^{\circ} \mathrm{C}$ decreases the carbon solubility and so eventually, a larger size and volume fraction are produced. This takes some time to reach equilibrium and these times are longer for the unirradiated material because there is no irradiation-enhanced diffusion.

It can be seen that the radiation promotes an increase in rates of growth through coarsening in the irradiated case. When the model is run without radiation enhanced diffusion, the irradiated and non-irradiated curves superimpose in all cases. Therefore, it is clear that radiation enhanced diffusion, and not thermodynamically-induced phase instability, is the main contributor to this effect. 
The drop in the apparent particle size in Fig. 1 (b), after about 100 hours, when radiation is beginning, may suggest that there are some new particles nucleated. This is considered in the modelling as nucleation of particles is considered in every stage of the modelling. In addition, irradiation enhanced diffusion and solubility changes could result in an increase in nucleation rate and therefore induce the nucleation of new particles. These newly nucleated particles reduce the overall average size of the particles. However, close examination of the number of particles within the simulation cell shows that there is no increase of particle numbers, i.e. no nucleation taking place. This is due to the extremely low carbon concentration remaining in the matrix (very close to equilibrium values).

The drop in fact represents a real increase in the mean size, if it is assumed that the same volume fraction increment is maintained. This will occur at early stages of coarsening because, for a fixed volume fraction increment, the mean size of smaller particles will reduce more rapidly than it will increase for larger particles and result in a slower increase or even decrease in the overall average particle size. This can be shown mathematically as follows. Suppose there are two particles, the bigger one with radius $r_{L}$ and the smaller one with radius $r_{S}$, the number average of the size of the two particles, $\bar{r}$, is then

$$
\bar{r}=\frac{1}{2}\left(r_{L}+r_{S}\right)
$$

Therefore

$$
d \bar{r}=\frac{1}{2}\left(d r_{L}+d r_{S}\right)
$$

The volume of the two particles (assumed spherical for simplicity) is 


$$
V=\frac{4}{3} \pi\left(r_{L}^{3}+r_{S}^{3}\right)
$$

Under coarsening conditions, $\mathrm{V}$ is a constant, therefore

$$
d V=4 \pi\left(r_{L}^{2} d r_{L}+r_{S}^{2} d r_{S}\right)=0
$$

Or

$$
d r_{S}=-\frac{r_{L}^{2}}{r_{S}^{2}} d r_{L}
$$

Therefore

$$
d \bar{r}=\frac{1}{2}\left(1-\frac{r_{L}^{2}}{r_{S}^{2}}\right) d r_{L}
$$

As $r_{L}>r_{S}$ and $d r_{L}>0$ (larger particles grow bigger), thus $d \bar{r}<0$, the average of the two particles decreases.

The real system is much more complex than the two particle system, but the principle is the same. At the beginning of coarsening, some particles dissolve without a significant reduction in the total number of particles, the average particle size decreases or increases very slowly. Eventually, coarsening is accompanied by appreciable reductions in the number of particles, i.e. a sufficient number of small particles will disappear and true coarsening of the larger particles begins. At this point, after about 10000 hours, the mean size increases more rapidly than for systems with lower coarsening rates (unirradiated material), and the size curves for the irradiated and unirradiated materials cross over. This situation is confirmed by Fig. 1 (a), where the rate of volume fraction increase in the irradiated material is seen to be greater than for unirradiated material for all times after growth begins (after about 100 hours). 
Huge differences exist between experiment and theory for the volume fraction measurements of Faulkner [16]. This must be at least partly due to the limitations involved in the image-processed SEM experimental measurements because the volume fraction of iron carbide permitted by the concentration of carbon $(0.195$ at $\%)$ is more than an order of magnitude lower than the measured value if the composition of the carbides is strictly $\mathrm{Fe}_{3} \mathrm{C}$.

Another example of volume fraction and particle size of intergranular $\mathrm{Fe}_{3} \mathrm{C}$ particles as a function of heat treatment time and temperature is shown in Fig. 2 for alloy ALLOY A (High Ni, low copper). Again, the predictions are in reasonable agreement with experimental measurements. Unlike in ALLOY B, here there are no drops in both curves. This is because that precipitation in ALLOY A is somehow slower and the maximum volume fraction is not reached by the end of the stress relieving heat treatment. Consequently, a continuous nucleation and growth process is observed and there is no dissolution.

\section{Irradiation induced precipitation of Cu-rich particles}

Fig. 3 shows the forecast and observed precipitate details for the intra-granular copperrich precipitate in high Ni-high $\mathrm{Cu}$ alloy, ALLOY B. According to MTDATA phase calculations, the $\mathrm{Cu}$-rich phase has a basic composition of $\mathrm{Cu}_{2} \mathrm{Fe}$ and has a $\mathrm{BCC}$ structure, which is different from those reported [3]. As the formation and growth of this phase depends on the diffusion of copper, copper is assumed to be the rate controlling element in this case. Parameters used are given in Table 2. The fits between measured and predicted size are good for Buswell's measurements [5], but not so good in relation to Faulkner's measurements [16]. The Faulkner volume fractions 
suffer from the same problem as discussed in relation to Fig. 1. The mean size of the particles is predicted to increase with irradiation. It is interesting that Faulkner observed a reduction in mean particle size with irradiation for this alloy only; the others in the series investigated all experienced increase particle sizes after irradiation [1]. The copper-rich phase shows nucleation after 2 years at $255^{\circ} \mathrm{C}$. In fact, it is present after at least 0.5 years. The difference is due to the incorrect choice of interfacial energy because so little is known about the crystal structure, composition and interface structure of clusters of this phase, although Miller and his group have made some progress in this understanding with the 3D Atom Probe [3].

\section{Irradiation assisted precipitation of Mo2C particles}

Fig. 4 shows the predictions (lines) for intra-granular $\mathrm{Mo}_{2} \mathrm{C}$. Diffusion of Mo in steels is much slower than that of carbon and the formation and growth of $\mathrm{Mo}_{2} \mathrm{C}$ depends mainly on the availability of Mo. Therefore, molybdenum is assumed to be rate controlling in this case. Parameters used are given in Table 2. Reasonable fits between the Faulkner [16] and Buswell [5] experimental measurements (symbols) are seen.

As in the case of $\mathrm{Fe}_{3} \mathrm{C}$, there are drops in both the volume fraction and size curves after the stress relieving treatment due to higher Mo and $\mathrm{C}$ solubilities at higher temperatures. Unlike the situation of $\mathrm{Fe}_{3} \mathrm{C}$, however, the volume fraction of $\mathrm{Mo}_{2} \mathrm{C}$ does not increase when the temperature is lowered again to $255^{\circ} \mathrm{C}$ in the unirradiated case. This is expected as the mobility of Mo at such a low temperature is very low. But carbon still has sufficient mobility at such temperatures. When irradiation is considered, both the volume fraction and particle size of $\mathrm{Mo}_{2} \mathrm{C}$ approach equilibrium limits with increasing time. This clearly demonstrates the effects of irradiation enhanced diffusion. 


\section{Effects of the content of $\mathrm{Ni}$ and $\mathrm{Cu}$}

The effects of copper content on $\mathrm{Cu}$-rich precipitates are obvious. This type of particles is predicted to precipitate in most of the alloys studied except ALLOY A which has the lowest $\mathrm{Cu}$ content. In this alloy the $\mathrm{Cu}$ is too low for the model to predict any formation of the $\mathrm{Cu}$-rich particles. Fig. 5 shows the comparison between predicted intra-granular Cu-rich precipitate behaviour in two alloys, ALLOY B (high Ni/high $\mathrm{Cu}$ ) and ALLOY $\mathrm{C}($ low $\mathrm{Ni} / \mathrm{high} \mathrm{Cu})$. The volume fraction of $\mathrm{Cu}$-rich particle in ALLOY B is much higher than that in ALLOY C (Fig. 5 (a)).

One may argue that this is the effect of higher Ni content in ALLOY B. However, close examination shows this is an effect of the $\mathrm{Cu}$ content in ALLOY B. The ratio of maximum volume fraction predicted for ALLOY B and ALLOY C $(0.00937 / 0.00785 \sim 1.2)$ is nearly equal to the ratio of the $\mathrm{Cu}$ content in ALLOY B and ALLOY C (0.62/0.52 1.2). But MTDATA predicts a higher Cu solubility in ALLOY $\mathrm{B}$ than in ALLOY $\mathrm{C}$ by a factor of 1.2. This can be considered as the effect of higher Ni content in ALLOY B since MTDATA predicts similar Cu solubility ( $\sim 0.95$ of that of ALLOY B) in ALLOY A, which has similar Ni content to ALLOY B. Therefore, higher Ni tends to keep more $\mathrm{Cu}$ in solution and results in lower volume fraction of $\mathrm{Cu}$-rich particles if $\mathrm{Cu}$ content is kept constant. Therefore the copper content appears to be the dominant factor in determining the $\mathrm{Cu}$-rich particle volume fraction.

Higher $\mathrm{Cu}$ solubility due to higher Ni content in ALLOY B also affects the growth and coarsening of $\mathrm{Cu}$-rich particles. From Eqn. (6), higher $\mathrm{Cu}$ solubility $\left(C_{\infty}\right)$ results in higher $\mathrm{Cu}$ concentration at the interface between $\mathrm{Cu}$-rich particles and the matrix. 
During the growth stage, this reduces the $\mathrm{Cu}$ concentration gradient towards the particle if the concentration in the matrix is the same, and hence results in slower growth. The faster growth rate of Cu-rich particles in ALLOY B as compared with that in ALLOY C shown in Fig. 5(b) is due to higher $\mathrm{Cu}$ content. In theory, the higher interfacial $\mathrm{Cu}$ concentration could result in faster dissolution of smaller particles, thus faster coarsening rate. This is not so evident in Fig. 5(b) as the solubility itself is very low.

Fig. 6 describes the inter-granular $\mathrm{Fe}_{3} \mathrm{C}$ precipitation in high and low $\mathrm{Ni}$ alloys ALLOY B and ALLOY C. Both volume fraction and mean particle size predictions seem to indicate that there is less $\mathrm{Fe}_{3} \mathrm{C}$ in the high Ni material. This is true because that the ratio of the volume fraction of grain boundary $\mathrm{Fe}_{3} \mathrm{C}$ particles in ALLOY $\mathrm{C}$ and ALLOY B $(0.002588 / 0.001963 \sim 1.3)$ is much higher than the ratio of the carbon content in the two alloys $(0.51 / 0.42 \sim 1.2)$. This indicates that the higher volume fraction of $\mathrm{Fe}_{3} \mathrm{C}$ in ALLOY C can not be attributed to the higher carbon content alone and there is some contribution due to the effect of lower Ni content in ALLOY C as all other elements have roughly the same concentration. MTDATA results show that higher Ni content in ALLOY B increases the solubility of carbon in the matrix by more than an order of magnitude at various temperatures as compared to ALLOY C. In addition, higher Ni content in ALLOY B also decreases the solubility of Mo which forms $\mathrm{Mo}_{2} \mathrm{C}$ and shares carbon with $\mathrm{Fe}_{3} \mathrm{C}$. Therefore, there would be more carbon available for precipitation of $\mathrm{Fe}_{3} \mathrm{C}$ in low $\mathrm{Ni}$ alloy ALLOY $\mathrm{C}$ even if the carbon content is the same as in ALLOY B. 
Fig. 7 shows the effect of copper on $\mathrm{Fe}_{3} \mathrm{C}$ formation by showing that more $\mathrm{Fe}_{3} \mathrm{C}$ is formed in the high Ni-high Cu alloy (ALLOY B) than in ALLOY A (high Ni-low $\mathrm{Cu}$ ). No Cu-rich precipitation is predicted for ALLOY A because of the low $\mathrm{Cu}$ content. The main origin of the difference shown in the predicted $\mathrm{Fe}_{3} \mathrm{C}$ precipitation is thought to be due to the lower carbon content of ALLOY A. This can be confirmed by comparing the volume fraction of $\mathrm{Fe}_{3} \mathrm{C}$ and carbon concentration in the two alloys. The ratio of the volume fraction of $\mathrm{Fe}_{3} \mathrm{C}$ in ALLOY B to that in ALLOY A is 1.08 which is very close to the ratio of carbon in ALLOY B to that in ALLOY A $(\sim 1.14)$.

Clearly the $\mathrm{Fe}_{3} \mathrm{C}$ nucleation times are ten times longer in ALLOY A than in any of the other alloys reviewed (ALLOY B and ALLOY C). This is partly due to the low carbon content in this alloy. It is a feature that needs attention because it means that in alloys with $\mathrm{C}$ levels below $0.037 \mathrm{wt} \%$, the carbide precipitation has not fully occurred before the materials goes into service. Indeed for pure thermal treatments, full precipitation has not occurred until 0.5 year. Fortunately irradiation brings the end of the growth stage at $255{ }^{\circ} \mathrm{C}$ much further forward. However, the lower copper content in ALLOY A seems to play an additional role. MTDATA shows that the solubility of carbon in ALLOY A is one order of magnitude higher than that in ALLOY B. This suggests that copper promotes the formation of carbides, such as $\mathrm{Fe}_{3} \mathrm{C}$ and $\mathrm{Mo}_{2} \mathrm{C}$. The higher carbon solubility in ALLOY A retards the formation and growth of $\mathrm{Fe}_{3} \mathrm{C}$ because less $\mathrm{C}$ is available for precipitation at the service temperature $\left(255^{\circ} \mathrm{C}\right)$. Low carbon content and high carbon solubility result in that no carbide precipitation occurs during stress relief of ALLOY A. 
Generally, high $\mathrm{Ni}$ seems to promote less inter-granular $\mathrm{Fe}_{3} \mathrm{C}$. Irradiation produces large precipitates after long times. Low copper materials, according to the theory, should not produce a $\mathrm{Cu}$-rich phase, but there is still a need for more thermodynamic data on this phase. Carbon levels are critical to ensure that full carbide precipitation has occurred before materials enter reactor service (greater than $0.037 \mathrm{wt} . \%$ is required).

\section{CONCLUSIONS}

A new kinetic model for inter-and intra-granular precipitation in steels has been developed to take into account neutron irradiation. In general, precipitation in reactor pressure vessel steels shows reasonable fits between model outputs and experimental observations. More specifically, the following conclusions about general behaviour can be made.

- Irradiation enhanced precipitation in RPV steels is accelerated mainly because of the radiation-enhanced diffusion effect, and not by any thermodynamic driving force considerations.

- Irradiation is predicted to produce larger precipitates after long times at service temperature in all cases.

- High Ni seems to promote less inter-granular $\mathrm{Fe}_{3} \mathrm{C}$. High $\mathrm{Cu}$ speeds up the formation and growth of inter-granular $\mathrm{Fe}_{3} \mathrm{C}$ because high $\mathrm{Ni}$ increases the $\mathrm{C}$ solubility and high $\mathrm{Cu}$ reduces $\mathrm{C}$ solubility in $\mathrm{Fe}$.

- Low copper materials, according to the theory, should not produce a $\mathrm{Cu}$-rich phase, but there is still a need for more thermodynamic data on this phase. 
- Carbon levels are critical to ensure that full carbide precipitation has occurred before material enters reactor service (greater than $0.037 \mathrm{wt} . \%$ is required).

\section{REFERENCES}

[1] R.G. Faulkner, Z. Lu, and D. Ellis and T.J. Williams, Effects of neutron irradiation on precipitation in reactor pressure vessel steels, Journal of ASTM International 2 (2006) 165-179.

[2] J.M. Hyde, D. Ellis, C.A. English, and T.J. Williams, Microstructural evolution in high Nickel submerged arc welds, ASTM STP 1405 (2001) 262-288.

[3] M.K. Miller, K.F. Russell, M.A. Sokolov, and R.K. Nanstad, Atom probe tomography characterization of radiation-sensitive KS-01 weld, J. Nuc. Mat. 320 (2003) 177-183.

[4] S.E. Cumblidge, A.T. Motta, G.L. Catchen,, G. Brauer, and J. Bohmert, Evidence for neutron irradiation-induced metallic precipitates in model alloys and pressurevessel weld steel, J. Nuc. Mat. 320 (2003) 245-257.

[5] J.T. Buswell, 1983, IAEA coordinated Research Programme Report, UKAEA, April 1983

[6] R.H. Davies, A.T. Dinsdale, T.G. Chart, T.I. Barry, and M.H. Rand, Application of MTDATA to the modelling of multicomponent equilibria,High Temp. Sci. 26 (1990) 251-262.

[7] Y.F. Yin and R.G. Faulkner, Simulation of precipitation in ferritic steels, Materials Science and Technology 19 (2003) 91-98.

[8] Y. F. Yin and R.G. Faulkner, A new modelling approach to microstructural evolution in ferritic steels, Energy Technology 21 (2002) 1247-1256. 
[9] Y.F. Yin and R.G. Faulkner, Continuum damage mechanics modelling based on simulations of microstructural evolution kinetics, Materials Science and Technology 22 (2006) 929-936.

[10] Y. F. Yin and R.G. Faulkner, Creep damage and grain boundary precipitation in power plant metals, Materials Science and Technology 21 (2005) 1239-1246.

[11] F.V. Nolfi, 1983, Phase Transformations during Irradiation, Applied Science, London.

[12] Z. Lu and R. G. Faulkner, to be published in Journal of Nuclear Materials Science.

[13] R.G. Faulkner, Combined grain boundary equilibrium and non-equilibrium segregation in ferritic/martensitic steels, Acta. Mat. 35 (1987) 2905-2914.

[14] W.C. Johnson et al, Influence of crystallography on aspects of solid-solid nucleation theory, Metall. Trans A 6A (1975) 911-919.

[15] R.G. Faulkner, Shenhua Song, P.E.J. Flewitt, and S.B. Fisher, Irradiationenhanced solute diffusion in alloys, J. Mat Sci. Lett. 16 (1997) 1191-1194. [16] R.G. Faulkner, 2001, LUEL reports, 1-3, Project MP/RRP/205, October 2001 


\section{CAPTIONS to Tables and Figures:}

Table 1 Alloy Compositions (wt.\%).

Table 2 Main parameters used in microstructural evolution simulations.

Table 3 Parameters used in calculating irradiation assisted diffusivity.

Figure 1. Simulated volume fraction (a) and particle size (b) of inter-granular $\mathrm{Fe}_{3} \mathrm{C}$ in ALLOY B compared with measurements of Faulkner [16] and Buswell [5].

Fig. 2. Comparison of measured and predicted $\mathrm{Fe}_{3} \mathrm{C}$ precipitation in high $\mathrm{Ni} / \mathrm{low} \mathrm{Cu}$ (ALLOY A) alloy

Figure 3. Simulated volume fraction and particle size of intra-granular $\mathrm{Cu}-\mathrm{rich}$ particles in ALLOY B compared with measurements of small unidentified particles by Buswell [5] and Faulkner [16].

Figure 4. Simulated volume fraction and particle size of intra-granular $\mathrm{Mo}_{2} \mathrm{C}$ in ALLOY B (high Ni/high Cu) compared with measurements by Buswell [5] and Faulkner [16].

Fig. 5 Comparison of predicted Cu-rich precipitation in Alloys ALLOY B (high Ni/ high $\mathrm{Cu}$ with ALLOY C (low Ni/high $\mathrm{Cu}$ ).

Fig. 6 Comparison of Predicted $\mathrm{Fe}_{3} \mathrm{C}$ Precipitation in Alloys ALLOY B (high $\mathrm{Ni} / \mathrm{high} / \mathrm{Cu}$ and ALLOY $\mathrm{C}($ low $\mathrm{Ni} /$ high $\mathrm{Cu}$ ) under irradiation conditions. 
Fig. 7. Comparison of Inter-granular $\mathrm{Fe}_{3} \mathrm{C}$ precipitation in high $\mathrm{Ni} / \mathrm{high} \mathrm{Cu}$ (ALLOY B) and high $\mathrm{Ni} /$ low $\mathrm{Cu}$ (ALLOY A) with and without irradiation. Note that the scale on the volume fraction curve is larger than for similar curves for ALLOY B (e.g., Fig. 5) 
Table 1 Alloy Compositions (wt.\%)

\begin{tabular}{|l|l|l|l|}
\hline Element & ALLOY A & ALLOY B & ALLOY C \\
\hline $\mathrm{C}$ & 0.037 & 0.042 & 0.051 \\
\hline $\mathrm{Si}$ & .53 & .38 & .37 \\
\hline $\mathrm{Mn}$ & 1.46 & 1.36 & 1.51 \\
\hline $\mathrm{Mo}$ & .35 & .41 & .47 \\
\hline $\mathrm{Ni}$ & 1.72 & 1.71 & .075 \\
\hline $\mathrm{Cr}$ & .095 & .05 & .038 \\
\hline $\mathrm{Cu}$ & .022 & .620 & .52 \\
\hline $\mathrm{S}$ & .007 & .009 & .012 \\
\hline $\mathrm{P}$ & .009 & .01 & .016 \\
\hline $\mathrm{As}$ & .003 & .028 & .018 \\
\hline $\mathrm{Sb}$ & .002 & .001 & .002 \\
\hline $\mathrm{Sn}$ & .002 & .002 & .009 \\
\hline $\mathrm{V}$ & .005 & .005 & .009 \\
\hline $\mathrm{Al}$ & .005 & .005 & .006 \\
\hline
\end{tabular}


Table 2. Main parameters used in microstructural evolution simulations

\begin{tabular}{|c|c|c|c|}
\hline & $\mathrm{Fe}_{3} \mathrm{C}$ & $\mathrm{Mo}_{2} \mathrm{C}$ & $\mathrm{Cu}$-rich \\
\hline Lattice parameter $(a, \mathrm{~nm})$ & 0.3649 & 0.3649 & 0.3649 \\
\hline Melting point $\left(T_{m}, \mathrm{~K}\right)$ & 1860 & 1860 & 1860 \\
\hline Grain size $(R, \mathrm{~mm})$ & 10 & 10 & 10 \\
\hline Grain boundary width $(d, \mathrm{~nm})$ & 1 & 1 & 1 \\
\hline Molar density of matrix $\left(\rho_{\alpha}, \mathrm{mol} / \mathrm{m}^{3}\right)$ & 140920 & 140920 & 140920 \\
\hline Grain boundary energy $\left(\sigma_{\mathrm{GB}}, \mathrm{J} / \mathrm{m}^{2}\right)$ & 0.505 & 0.505 & 0.505 \\
\hline $\begin{array}{l}\text { Precipitate facet-matrix interfacial energy } \\
\left(\sigma_{\alpha \theta}^{c}, \mathrm{~J} / \mathrm{m}^{2}\right)\end{array}$ & 0.5633 & 0.5633 & 0.5633 \\
\hline Molar density of phase $\left(\rho_{\theta}, \mathrm{mol} / \mathrm{m}^{3}\right)$ & 42700 & 43651 & 32000 \\
\hline $\begin{array}{l}\text { Pre-exponential constant for lattice diffusion } \\
\left(D_{0 S}^{T}, \mathrm{~m}^{2} / \mathrm{s}\right)\end{array}$ & 0.00000062 & 0.000063 & 0.0042 \\
\hline $\begin{array}{l}\text { Activation energy for lattice diffusion }\left(E_{S}^{T} \text {, }\right. \\
\mathrm{eV})\end{array}$ & 0.83 & 2.24 & 2.532 \\
\hline $\begin{array}{l}\text { Pre-exponential constant for grain boundary } \\
\text { diffusion }\left(D_{0 B}^{T}, \mathrm{~m}^{2} / \mathrm{s}\right)\end{array}$ & $6.2 \mathrm{E}-09$ & 0.003 & 0.0000042 \\
\hline $\begin{array}{l}\text { Activation energy for grain boundary } \\
\text { diffusion }\left(E_{B}^{T}, \mathrm{eV}\right)\end{array}$ & 0.415 & 1.9864 & 1.266 \\
\hline Interfacial energy $\left(\sigma_{\alpha \theta} \mathrm{J} / \mathrm{m}^{2}\right)$ & 0.67 & 0.175 & 0.24 \\
\hline Contact angle (degrees) & 30 & 90 & 90 \\
\hline$\Delta H(\mathrm{~J} / \mathrm{mol})$ & 44862 & 197824 & 89809 \\
\hline$\Delta S(\mathrm{~J} / \mathrm{mol} / \mathrm{K})$ & 26.52 & 47.92 & -20.99 \\
\hline $\mathrm{Cg}$ & 0.0007585 & 0.002381 & 0.0054367 \\
\hline$C \mathrm{c}$ & 0.9514229 & 0.001191 & 0.9514229 \\
\hline
\end{tabular}


Table 3 Parameters used in calculating irradiation assisted diffusivity

$\begin{array}{ll}\text { grain size in microns }(R, \mu \mathrm{m}) & 10 \\ \text { initial dislocation density }\left(\rho, \mathrm{m}^{-2}\right) & 1.00 \mathrm{E}+16 \\ \text { bias parameter } Z_{\mathrm{I}} & 1.1 \\ \text { Activation energy for dislocation formation } & 0.1 \\ (E d, \mathrm{eV} / \text { atom }) & 528 \\ \text { temperature }(T, \mathrm{~K}) & 1.00 \mathrm{E}-08 \\ \text { Neutron dose rate }\left(G, \mathrm{~s}^{-1}\right) & 0.01 \\ \text { dose correction } B & 5.00 \mathrm{E}-06 \\ \text { Interstitial diffusion }\left(D_{0 I}, \mathrm{~m}^{2} / \mathrm{s}\right) & 0.3 \\ \text { interstitial diffusion }\left(E_{m I}, \mathrm{eV} / \mathrm{atom}\right) & 5.00 \mathrm{E}-05 \\ \text { vacancy diffusion }\left(D_{0 V}, \mathrm{~m}^{2} / \mathrm{s}\right) & 1.4 \\ \text { vacancy diffusion }\left(E_{m v}, \mathrm{eV} / \mathrm{atom}\right) & 1.43 \mathrm{E}-10 \\ \text { jump distance of self-interstitials }(b, \mathrm{~m}) & 1.4 \\ \text { vacancy formation energy }\left(E_{v f}, \mathrm{eV} / \mathrm{atom}\right) & \end{array}$



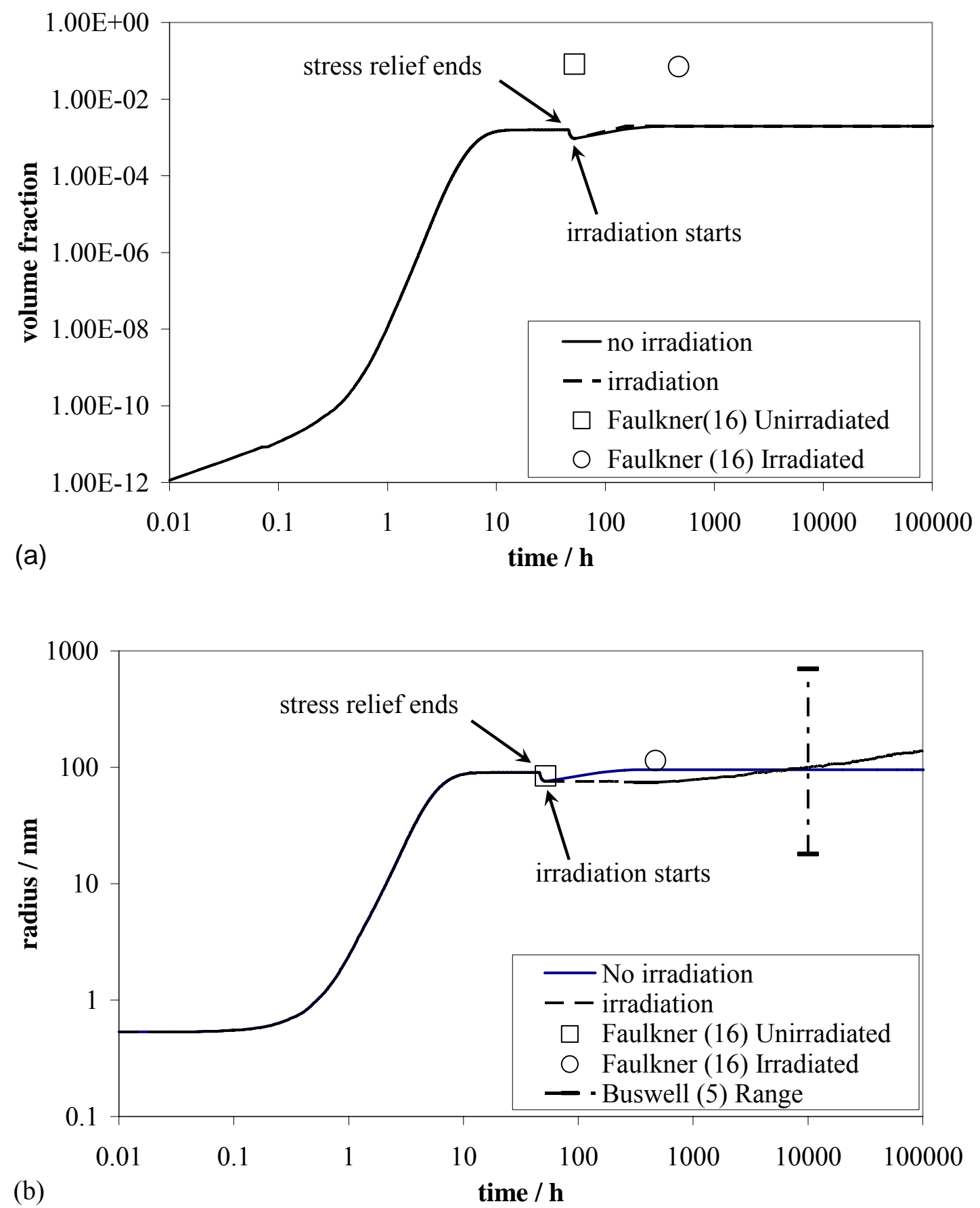

Figure 1. Simulated volume fraction and particle size of inter-granular $\mathrm{Fe}_{3} \mathrm{C}$ in ALLOY B compared with measurements of Faulkner and Buswell. 

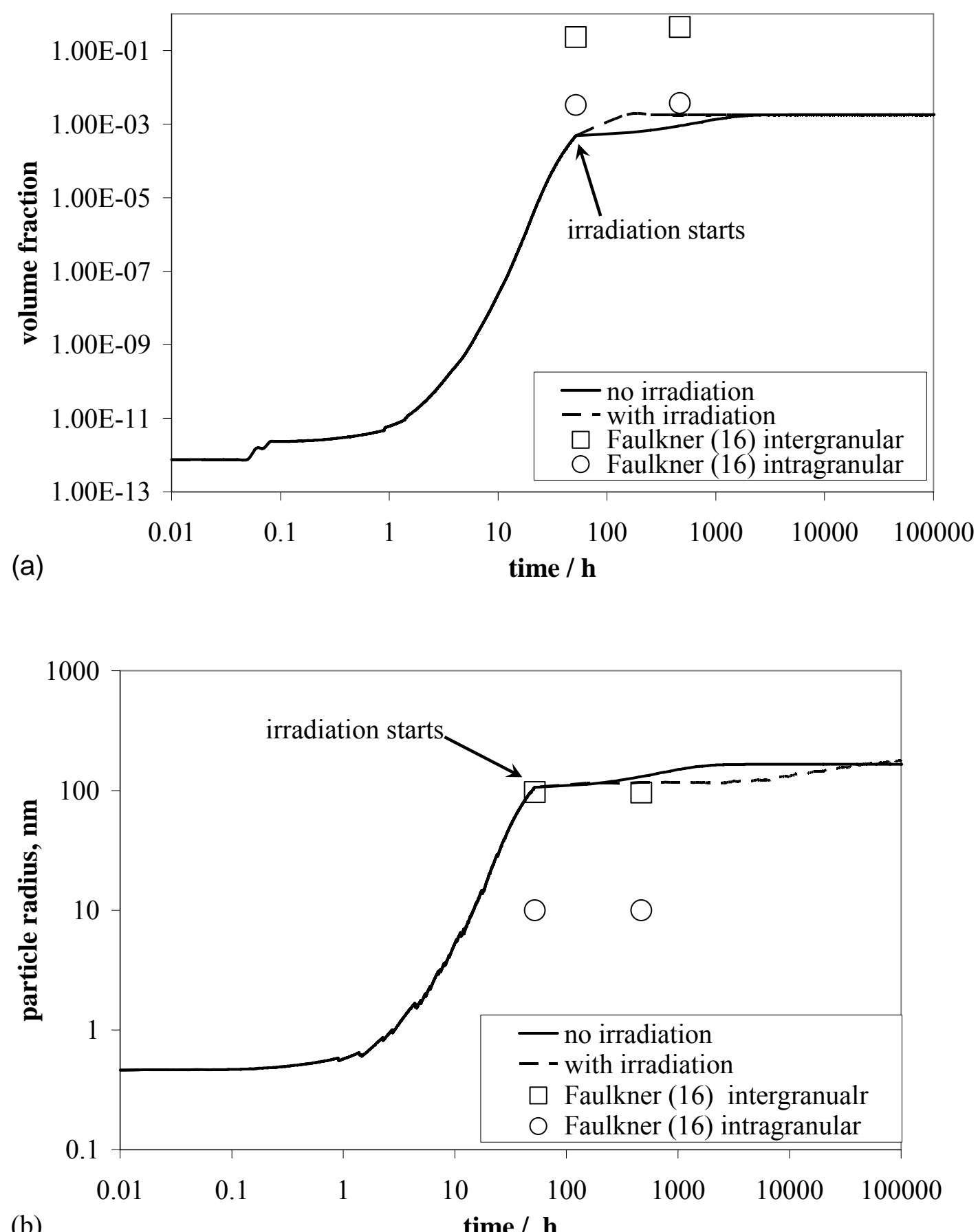

Fig. 2. Comparison of measured and predicted $\mathrm{Fe}_{3} \mathrm{C}$ precipitation in high Ni/low Cu (ALLOY A) alloy 

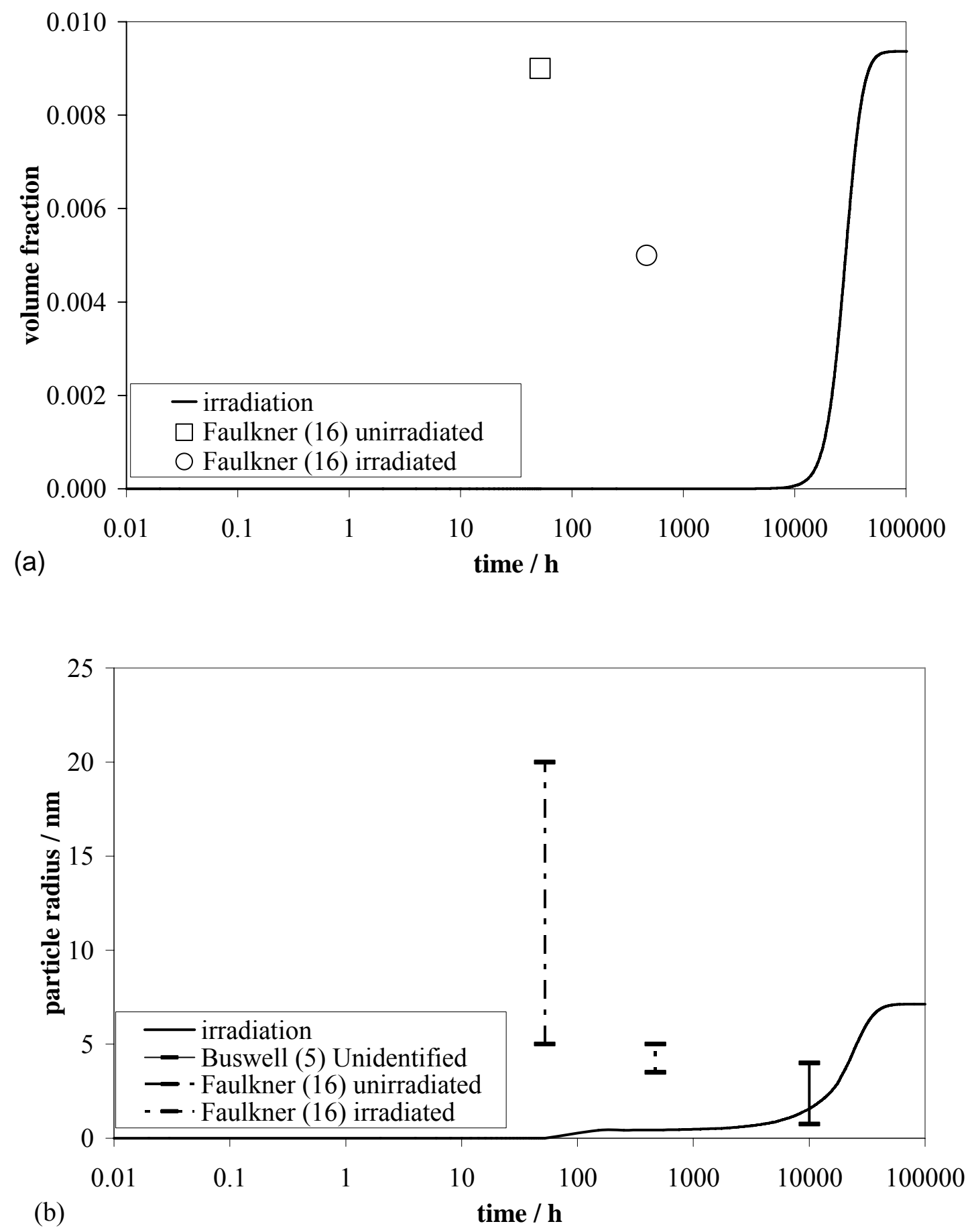

Figure 3. Simulated volume fraction and particle size of intra-granular $\mathrm{Cu}-$ rich particles in ALLOY B compared with measurements of small unidentified particles by Buswell (5) and Faulkner (16). 

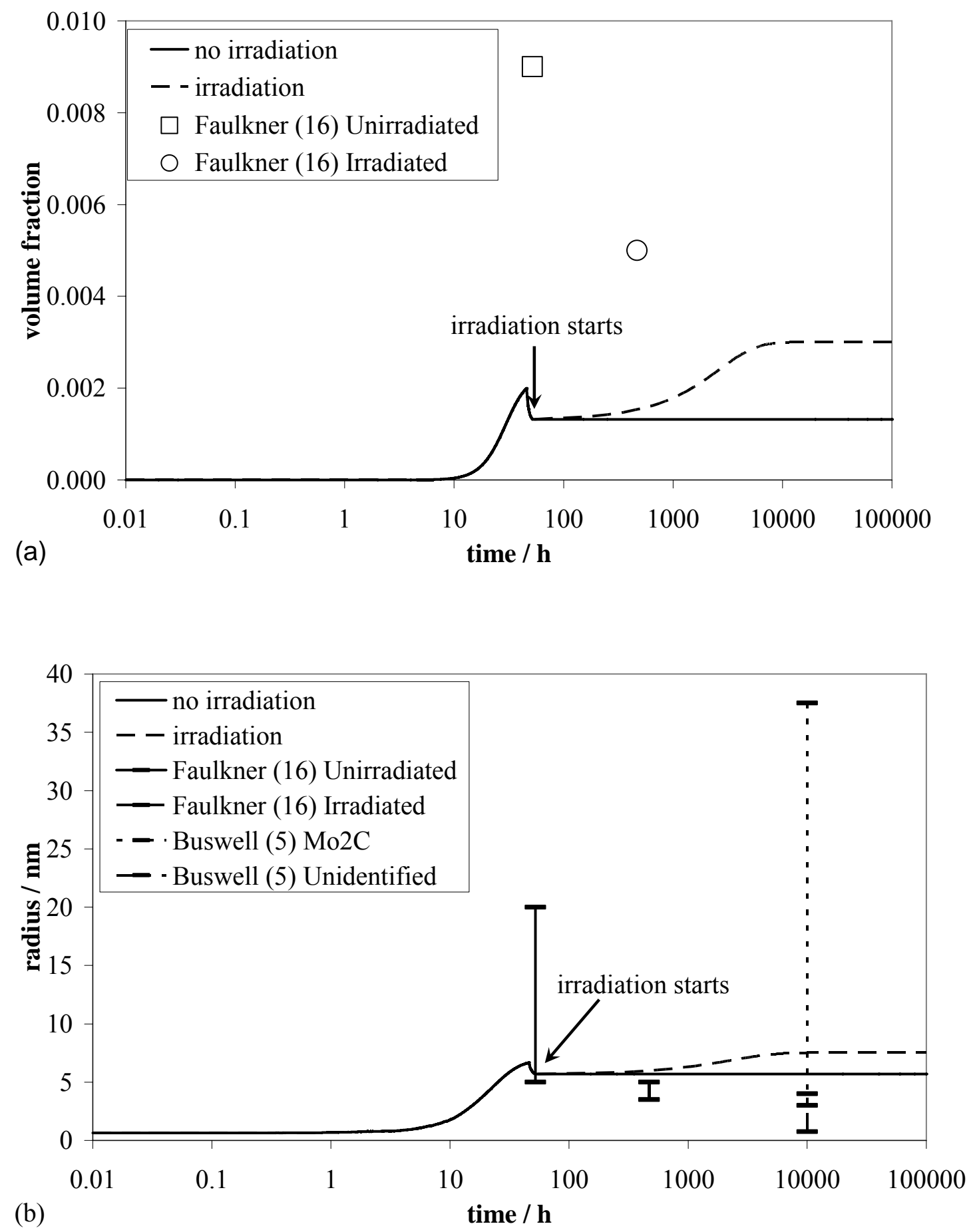

Figure 4. Simulated volume fraction and particle size of intra-granular $\mathrm{Mo}_{2} \mathrm{C}$ in ALLOY B (high Ni/high $\mathrm{Cu}$ ) compared with measurements by Buswell (5) and Faulkner (16). 

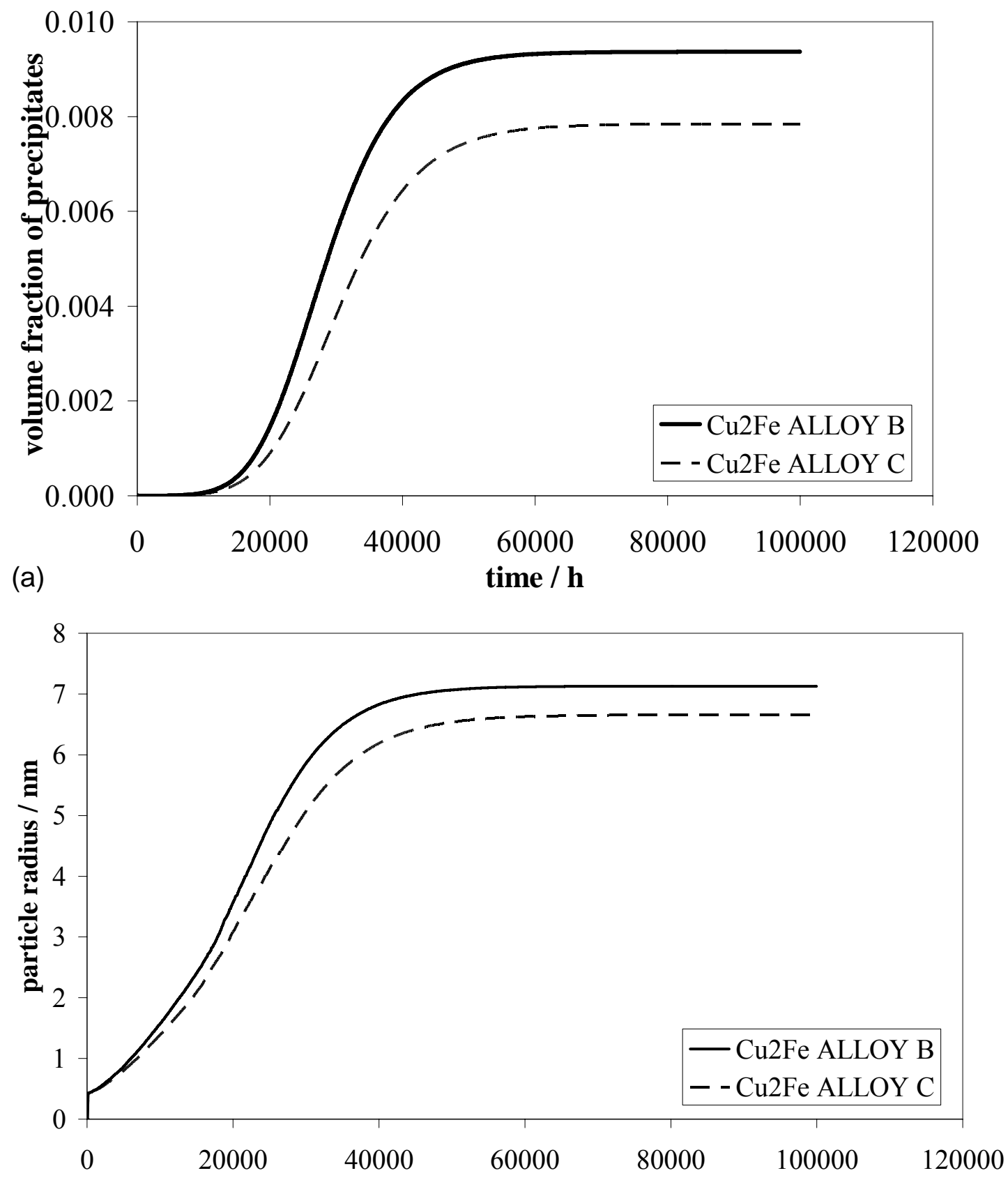

(b) time / h

Fig. 5 Comparison of predicted Cu-rich precipitation in Alloys ALLOY B (high $\mathrm{Ni}$ / high $\mathrm{Cu}$ with ALLOY C (low Ni/high $\mathrm{Cu}$ ). 

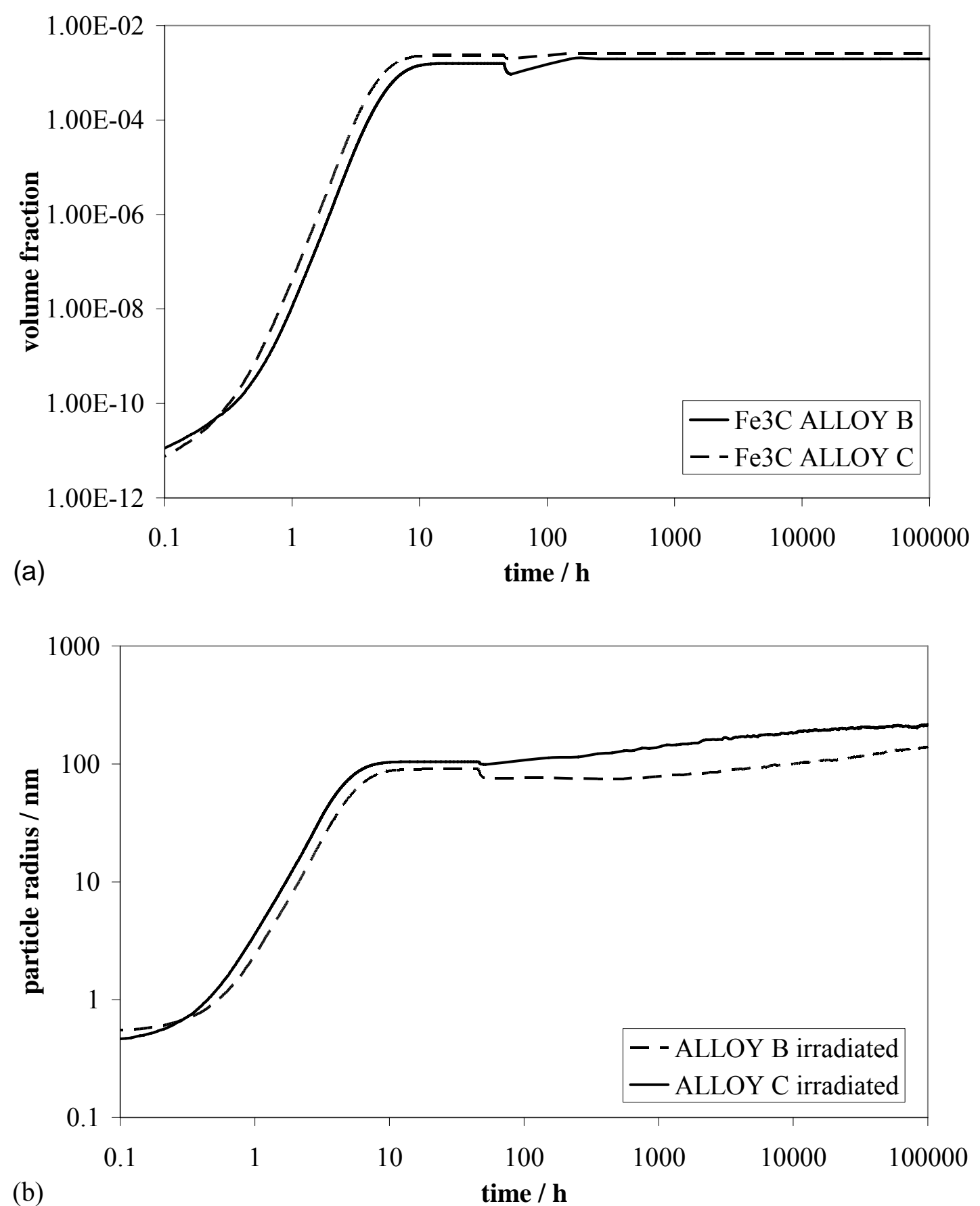

Fig. 6 Comparison of Predicted $\mathrm{Fe}_{3} \mathrm{C}$ Precipitation in Alloys ALLOY B (high $\mathrm{Ni} /$ high/Cu and ALLOY C (low Ni/high $\mathrm{Cu}$ ) under irradiation conditions. 

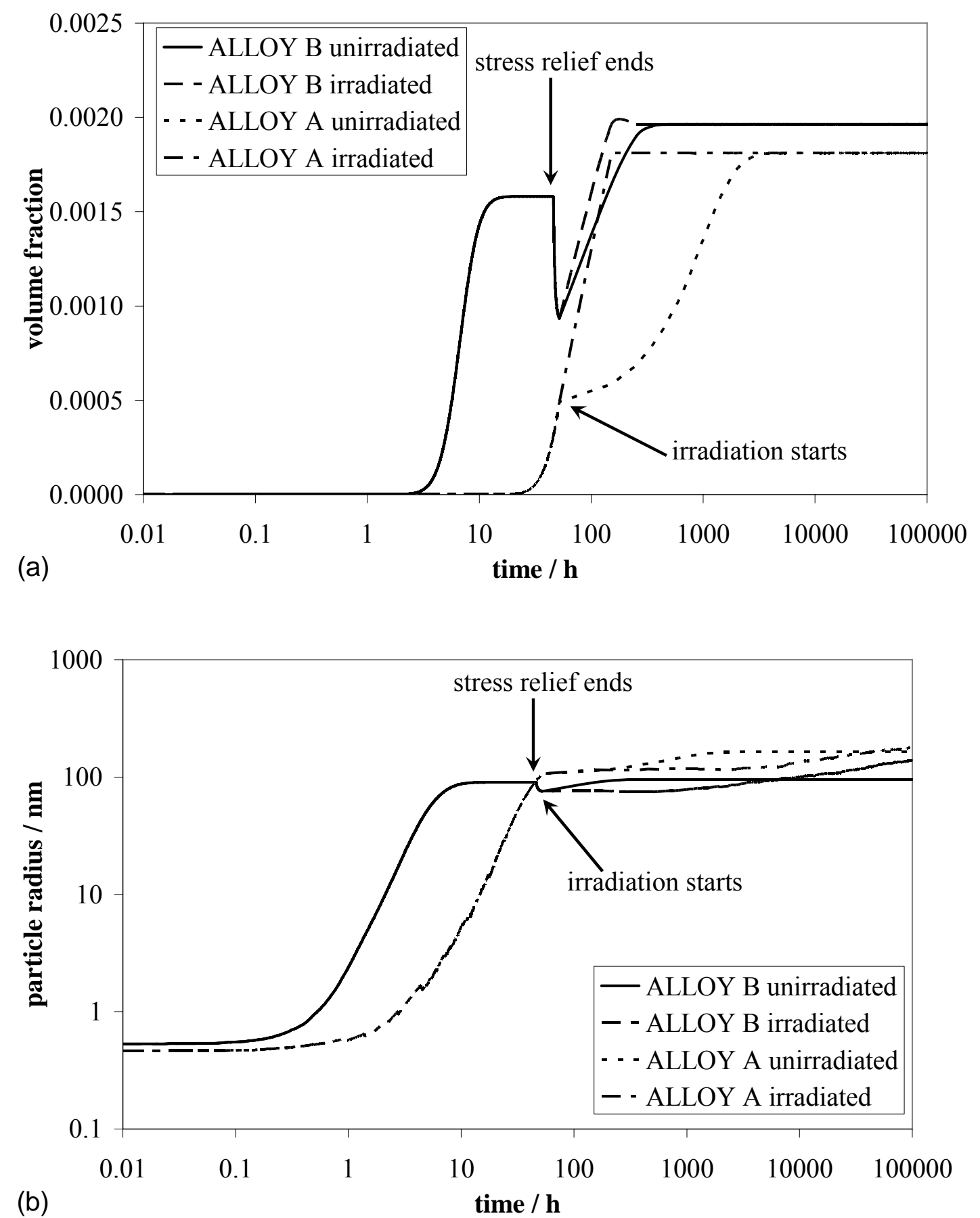

Fig. 7. Comparison of Inter-granular $\mathrm{Fe}_{3} \mathrm{C}$ precipitation in high $\mathrm{Ni} / \mathrm{high} \mathrm{Cu}$ (ALLOY B) and high Ni/low Cu (ALLOY A) with and without irradiation. Note that the scale on the volume fraction curve is larger than for similar curves for ALLOY B (e.g., Fig. 5) 